\title{
Endotoxin Induction of Tumor Necrosis Factor Is Enhanced by Acid-labile Interferon- $\alpha$ in Acquired Immunodeficiency Syndrome
}

\author{
Allan S. Lau*‡ and John F. Livesey* \\ *Division of Infectious Diseases, Department of Pediatrics, The Hospital for Sick Children, and \\ ${ }^{\ddagger}$ Department of Microbiology, University of Toronto, Toronto, Ontario, Canada M5G 1 X8
}

\begin{abstract}
High levels of an acid-labile IFN- $\alpha$ have been demonstrated in the sera of patients with symptomatic HIV infection. IFNs have been shown to enhance the cytotoxic and antiproliferative actions of tumor necrosis factor (TNF), which is a potent mediator of inflammation and sepsis. We show that the acid-labile IFN- $\alpha$ present in AIDS sera can induce TNF synthesis and sensitize blood monocytes (BM) to endotoxin stimulation resulting in further synthesis of TNF in vitro. TNF production by BM from patients with HIV infections and normal controls was measured by a cytotoxicity assay on L929 cells using human TNF $\alpha$ as a standard. BM from AIDS patients spontaneously produce high levels of TNF and are hypersensitive to endotoxin stimulation, resulting in enhanced synthesis of TNF. In determining the mechanism involved, we demonstrated that treatment of normal BM with AIDS sera results in induction of TNF. Neutralization of the acid-labile IFN- $\alpha$ in AIDS sera with polyclonal anti-IFN- $\alpha$ antibodies results in diminution of TNF induction. In addition, pretreatment of normal BM with AIDS sera, IFN- $\alpha$, or IFN- $\gamma$ renders the cells hypersensitive to endotoxin. Consequently, activation of the TNF system by the acid-labile IFN- $\alpha$ contributes to some of the physiological disturbances, such as the wasting syndrome, and to the pathophysiology of sepsis in AIDS patients.
\end{abstract}

\section{Introduction}

High levels of an unusual acid-labile IFN- $\alpha$ have been documented in sera of patients with HIV infection $(1,2)$ and are implicated in the immunopathogenesis of AIDS. Persistently elevated levels of IFN and its inducible enzyme, $2^{\prime}, 5^{\prime}$-linked oligoadenylate synthetase, in patients with HIV infection is indicative of disease progression from AIDS-related complex to $\operatorname{AIDS}(3,4)$. Recently we have demonstrated downregulation of IFN- $\alpha$ receptor expression on blood mononuclear cells from AIDS patients by the acid-labile IFN- $\alpha$ and consequent hyporesponsiveness of the cells to IFN- $\alpha$ treatment in vitro (5). Although the regulatory significance of this acid-labile IFN- $\alpha$ subtype in the pathogenesis of AIDS remains to be determined, IFNs have been shown to enhance the cytotoxic, tu-

Address reprint requests to Dr. Allan S. Lau, Division of Infectious Diseases, The Hospital for Sick Children, 555 University Avenue, Toronto, Ontario, Canada M5G-1X8.

Received for publication 28 October 1988 and in revised form 22 February 1989.

J. Clin. Invest.

(C) The American Society for Clinical Investigation, Inc.

0021-9738/89/09/0738/06 \$2.00

Volume 84, September 1989, 738-743 moricidal, antiviral, and antiproliferative activities of tumor necrosis factor (TNF) $)^{1}$ in vitro (6-9).

On the physiological level TNF mediates inflammation and sepsis, induces cachexia, and suppresses hematopoiesis $(10,11)$. Recent reports indicate that cytokines play an essential role in the induction of synthesis of TNF by monocytes and macrophages during inflammation (12-14). Therefore, abnormal expression of cytokines in disease processes such as HIV infections may result in increased TNF synthesis.

Activation of macrophages and monocytes involves a number of cellular processes. IFN- $\gamma$ sensitizes monocytes and renders them responsive to signals such as endotoxin (LPS) and foreign antigens (12-14). The combined actions of IFN- $\gamma$ and LPS result in enhancement of cytotoxic and tumoricidal activities mediated by matured macrophages and monocytes. Synergistic interaction between IFNs and LPS has been observed for the synthesis of IL-1 in human monocytes (15). A recent report also indicates that LPS and IFN- $\gamma$ act synergistically on human fibroblasts in the induction of factor B, which is one of the key proteins involved in the activation of the alternate complement pathway in inflammation (16).

In light of these synergistic interactions of LPS and IFN we investigated the induction of TNF synthesis by the cytokine and the bacterial endotoxin. We also determined the role of the acid-labile IFN- $\alpha$ present in AIDS sera in the enhancement of TNF synthesis and the sensitization of monocytes to LPS stimulation.

\section{Methods}

Patients. The patients in this study were homosexual males aged $25-45$ yr who had clinically defined HIV infections (groups III and IVc) according to surveillance criteria established by the Centers for Disease Control (17). The patients in group III had persistent lymphadenopathy without any constitutional disease $(n=6)$. In contrast, the patients in group IVc $(n=9)$ had recovered from opportunistic infections including disseminated cytomegalovirus, pneumocystis carinii pneumonia, or disseminated Herpes simplex. At the time of the study they were clinically stable without evidence of active opportunistic infections. All patients had positive IgG antibodies to HIV by ELISA assays. They were followed at the Toronto General Hospital AIDS clinic. The control subjects $(n=14)$ consisted of healthy laboratory personnel, medical students, and residents.

Cells and serum samples. PBMC were isolated from heparinized blood samples using Ficoll-Hypaque density gradient centrifugation $(5,18)$. The cells were incubated in a tissue culture dish (Falcon Plastics, Cockeysville, MD) at $37^{\circ} \mathrm{C}$ for $30 \mathrm{~min}$ for blood monocyte (BM) separation (5). The procedure was repeated twice to enrich the monocytic population. BM isolated were stained with a monoclonal antiMo2 (CD14) antibody (Mo2-RD1/KC56-FITC; Coulter Electronics Inc., Hialeah, FL) and subsequently studied by a cell analyzer (EPICS

1. Abbreviations used in this paper: BM, blood monocyte; TNF, tumor necrosis factor. 
profile analyzer; Coulter Electronics Inc.) to determine the purity of the cells. Serum samples obtained simultaneously were stored at $-70^{\circ} \mathrm{C}$ until the time of assay for IFN levels or used in TNF induction experiments.

Determination of IFN titers. The levels of IFN- $\alpha$ in the sera were determined by titrating for antiviral activity on T98G (glioblastoma) cells against National Institute of Allergy and Infectious Diseases reference standard G-023-901-527 $(5,18)$. In brief, $5 \times 10^{4} \mathrm{~T} 98 \mathrm{G}$ cells were seeded into each well of 96-well microtiter plates and incubated with twofold serial dilutions of patients' serum samples for $16 \mathrm{~h}$ and then challenged with encephalomyocardial virus ( 0.1 plaque forming units per cell). Virus-induced cytopathic effects were assessed by microscopic examination and by staining the cells with $0.1 \%$ crystal violet in $5 \%$ ethanol solutions. The IFN titer was defined as the reciprocal of the highest dilution of serum samples capable of protecting $50 \%$ of the cells from viral-induced cytopathic effects. All titers were expressed as international units/milliliter.

Acid lability of the IFN in the sera was determined by treating the serum samples with $0.2 \mathrm{M}$ hydrochloric acid to $\mathrm{pH} 2$ for $6 \mathrm{~h}$ at $25^{\circ} \mathrm{C}$ and subsequently neutralized to $\mathrm{pH} 7.4$ with $0.2 \mathrm{M}$ sodium hydroxide.

Effect of anti-IFN- $\alpha$ and $-\gamma$ antibodies. Sheep polyclonal antihuman IFN- $\alpha$ and $-\gamma$ antibodies (IFN Sciences Inc., New Brunswick, $\mathrm{NJ})$ were used to test the immunological specificity of the IFN subtype in the sera. Serum samples $(100 \mu \mathrm{l})$ from AIDS patients were pretreated with 2,000 neutralizing units of anti-human IFN- $\alpha$ or $-\gamma$ antibodies. The resultant mixtures were used for the treatment of BM for TNF synthesis.

Induction of TNF synthesis by sera from patients with HIV infection. Normal BM $\left(0.5 \times 10^{6}, n=14\right)$ in $0.375 \mathrm{ml}$ of RPMI medium, supplemented with $10 \%$ FCS, were treated with $0.125 \mathrm{ml}$ of serum samples from normal controls $(n=12)$, HIV group III $(n=6)$, and IVc $(n=9)$ patients. The IFN titers in the sera were determined as described above. After incubation at $37^{\circ} \mathrm{C}$ for $18 \mathrm{~h}$ culture supernatants were assayed in triplicate for TNF-mediated cytotoxicity (19-21).

Sensitization of monocytes to LPS induction of TNF. Normal BM $\left(0.5 \times 10^{6}, n=10\right)$ in $0.5 \mathrm{ml}$ of RPMI medium were treated with sera from normal controls $(n=10)$, IFN- $\alpha_{2}$ (Schering Corp., Kenilworth, NJ), IFN- $\gamma$ (Biogen Inc., Cambridge, MA), TNF $\alpha$ (Genentech Inc., South San Francisco, CA), or individual AIDS patients' sera $(n=4)$ containing the acid-labile IFN- $\alpha$. The final concentration of the normal and AIDS sera in the incubation medium was $25 \%$ of that of the original, whereas the concentration of the acid-labile IFN- $\alpha$ in the AIDS sera was $512 \mathrm{U} / \mathrm{ml}$. After incubation at $37^{\circ} \mathrm{C}$ for $18 \mathrm{~h}$ the cells were washed and stimulated with $10 \mu \mathrm{g} / \mathrm{ml}$ of LPS (Escherichia coli extract, Sigma catalogue No. L2630; Sigma Chemical Co., St. Louis, $\mathrm{MO}$ ) for $18 \mathrm{~h}$ for TNF induction.

Interaction of IFN- $\alpha$ or $-\gamma$ with LPS on TNF synthesis. Normal BM $\left(0.5 \times 10^{6}\right)$ in $0.5 \mathrm{ml}$ of RPMI 1640 medium were treated with varying concentrations of LPS, IFN- $\alpha_{2}$, or IFN- $\gamma$. To evaluate the interaction of IFN- $\alpha$ or $-\gamma$ with LPS on the induction of TNF synthesis, BM were treated with various concentrations of IFN $-\alpha$ or $-\gamma$ with $1.0 \mu \mathrm{g}$ of LPS. After incubation at $37^{\circ} \mathrm{C}$ for $18 \mathrm{~h}$ the culture supernatants were assayed for TNF activities.

TNF assay. TNF titers in supernatants from BM cultures were quantitated in 96-well microtiter plates by a cytotoxicity assay using L929 (mouse fibrosarcoma) cells. In brief, $5 \times 10^{4}$ cells were seeded into each well and incubated for $24 \mathrm{~h}$ at $37^{\circ} \mathrm{C}$ with twofold serial dilutions of the supernatants in $\alpha$-MEM medium containing $10 \%$ fetal bovine serum and $1 \mu \mathrm{g} / \mathrm{ml}$ of actinomycin D (catalogue No. 102008; Boehringer Mannheim Biochemicals, Indianapolis, IN). TNF-induced cytopathic effects were assessed by microscopic examination and by staining the cells with $0.1 \%$ crystal violet in $5 \%$ ethanol solutions. A unit of cytotoxicity was defined as the concentration at which $50 \%$ of the $\mathrm{L}$ cells were showing cytopathic effects after $24 \mathrm{~h}$. In each assay purified recombinant human TNF $\alpha\left(5 \times 10^{7} \mathrm{U} / \mathrm{mg}\right.$; Genentech Inc.) was used as a standard. To determine the specificity of the cytotoxic factors, monoclonal anti-TNF $\alpha$ antibodies (Genentech Inc.) were used to neutralize the cytotoxic effects of the culture supernatant.
Statistics. The results were analyzed for statistical significance with the nonpaired $t$ test.

\section{Results}

IFN titers in the sera of patients with HIV infections. To demonstrate the presence of the acid-labile IFN- $\alpha$ in the serum samples, IFN assays were performed on T98G cells. The IFN levels in the sera of patients with HIV groups III and IVc infections were determined to be $11.2 \pm 12(n=6$; range, $0-32)$ and $350 \pm 160(n=9$; range, 64-512) $\mathrm{U} / \mathrm{ml}$, respectively. All patients with group IVc infection had elevated levels of the acid-labile IFN- $\alpha$, whereas only four of six patients with group III infection had detectable IFN in their serum. The IFN subtype in the patients' sera could be neutralized by polyclonal anti-IFN- $\alpha$ antibodies or inactivated by acid treatment ( $\mathrm{pH} 2$ ), consistent with previous reports $(1,2,5)$. Preincubation of the samples with $2,000 \mathrm{U} / \mathrm{ml}$ of the anti-IFN- $\alpha$ antibodies before antiviral assays resulted in complete neutralization or at least a 16-fold (95\%) decrease in IFN activity. In normal controls $(n=14)$ assayed concurrently, no IFN was detectable in the serum.

Synthesis of TNF by BM from AIDS patients. The purity of $\mathrm{BM}$ used in the experiments was determined to be in the range of $85-95 \%$ by staining with anti-Mo2 (CD14) antibodies and analysis by the EPICS profile analyzer. To investigate the activation of the TNF system in AIDS we measured the synthesis of TNF by BM in patients with HIV infections. Supernatants of BM cultures from AIDS patients showed high levels of TNF $(18.7 \pm 7.0 \mathrm{U} / \mathrm{ml}, n=7, P<0.005)$ compared with those of the normal controls $(1.1 \pm 0.96 \mathrm{U} / \mathrm{ml}, n=14$; Fig. 1$)$. The cytotoxic factor in the supernatant was determined to be TNF $\alpha$ by neutralization experiments using a monoclonal anti-TNF $\alpha$ antibody (Genentech, Inc.). When the cells were treated with $10 \mu \mathrm{g} / \mathrm{ml}$ LPS there was an increase in TNF synthesis by the AIDS cells to a level of $48.5 \pm 16 \mathrm{U} / \mathrm{ml}(n=7, P<0.02)$ compared with that of the normal cells $(16 \pm 5 \mathrm{U} / \mathrm{ml}, n=7$; Fig. 1). Therefore, it appears that BM from AIDS patients are spontaneously producing high levels of TNF and are hypersensitive to LPS stimulation.

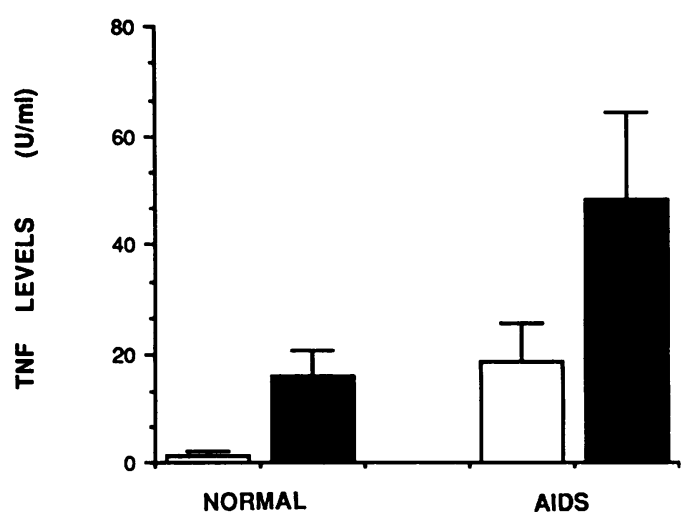

Figure 1. Synthesis of TNF by BM from patients with HIV infections. BM $\left(0.5 \times 10^{6}\right)$ from normal controls $(n=14)$ and patients with group IVc HIV infections $(n=7)$ were incubated at $37^{\circ} \mathrm{C}$ for 16 $h$ in the presence (solid bars) or absence (open bars) of LPS (10 $\mu \mathrm{g} / \mathrm{ml})$. Triplicate samples were assayed for TNF-mediated cytotoxicity (see Methods). 
Induction of TNF synthesis by the acid-labile IFN- $\alpha$. To investigate the effect of the acid-labile IFN- $\alpha$ on the regulation of TNF synthesis, normal BM were treated with sera from patients with group III and IVc HIV infections. When normal cells were treated with AIDS sera (group IVc, $n=9$ ) containing the acid-labile IFN- $\alpha$ (Fig. $2 d$ ), there was induction of TNF synthesis $(37.3 \pm 13 \mathrm{U} / \mathrm{ml}, P<0.005)$ compared with untreated controls $(1.1 \pm 0.96, n=14$; Fig. $2 a$ a). In contrast, sera from patients with group III infection $(n=6)$ containing low levels of the acid-labile IFN- $\alpha$ did not induce TNF synthesis significantly (Fig. $2 c$ ). When parallel experiments were performed on normal cells treated with normal sera, no induction of TNF synthesis was observed ( $n=12$; Fig. $2 b$ ).

To determine the agent in the AIDS sera responsible for the induction of TNF synthesis, the serum samples were treated with sheep polyclonal anti-IFN- $\alpha$ antibodies. This treatment neutralized the antiviral activity of the sera mediated by the acid-labile IFN- $\alpha$ with a concomittant $80 \%$ decrease in TNF induction by the reactants $(n=5$, Fig. $2 e$ ). Polyclonal antiIFN- $\gamma$ antibodies did not have significant effects on the TNF induction ability of the AIDS sera (results not shown). The results suggest that the agent in the AIDS sera mainly responsible for the TNF induction is the acid-labile IFN- $\alpha$.

Sensitization of monocytes to LPS induction of TNF. To investigate whether IFN was responsible for the hypersensitivity to LPS of blood monocytes from AIDS patients, normal BM were treated with IFN- $\alpha$, IFN- $\gamma$, TNF, and AIDS sera containing the acid-labile IFN- $\alpha$. After incubations at $37^{\circ} \mathrm{C}$ for $16 \mathrm{~h}$ the cells were washed and stimulated with $10 \mu \mathrm{g} / \mathrm{ml}$ of LPS. The results (Fig. 3) show that pretreatment with IFN- $\alpha$ or $-\gamma$ or AIDS sera renders the normal BM hypersensitive to LPS stimulation, resulting in further synthesis of TNF in vitro. The respective levels of TNF in the supernatants were significantly increased to $59 \pm 10 \mathrm{U} / \mathrm{ml}(n=7, P<0.05), 149 \pm 43 \mathrm{U} / \mathrm{ml}(n$ $=6, P<0.001)$, and $128 \pm 24 \mathrm{U} / \mathrm{ml}(n=4, P<0.001) \mathrm{com}$ pared with cells with normal sera pretreatment $(35 \pm 10.5, n$ $=10$ ). In contrast, pretreatment of cells with TNF did not enhance the responsiveness to LPS stimulation $(n=7)$. AIDS sera, when preneutralized with anti-IFN- $\alpha$ antibodies, did not

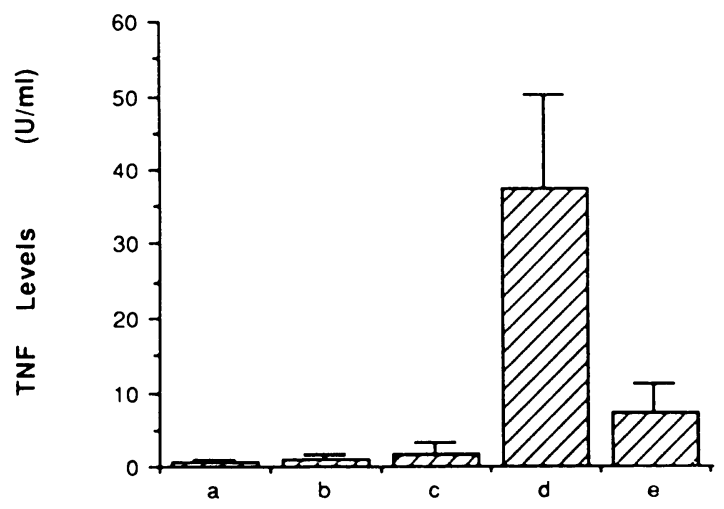

Figure 2. Induction of TNF synthesis by the acid-labile IFN- $\alpha$. BM $\left(0.5 \times 10^{6}\right)$ from normal individuals were incubated at $37^{\circ} \mathrm{C}$ for $16 \mathrm{~h}$ with: (a) controls, no treatment $(n=14) ;(b)$ normal sera $(n=12)$; (c) sera from patients with HIV group III infection $(n=6) ;(d)$ sera from patients with HIV group IVc infection $(n=9)$; $(e)$ sera from patients with HIV group IVc infection, preneutralized with antiIFN- $\alpha$ antibodies $(n=5)$. Triplicate samples of the culture supernatant were assayed for TNF levels (see Methods).

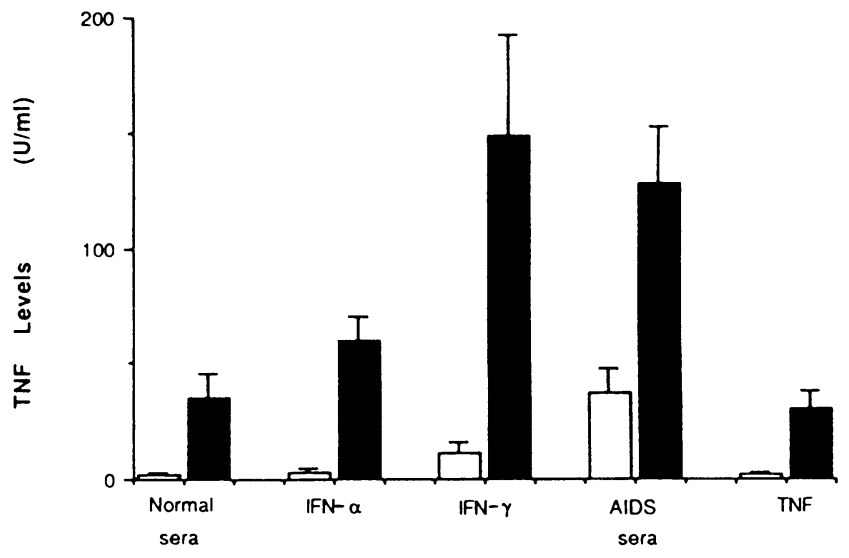

Figure 3. Sensitization of monocytes to LPS induction of TNF. BM $\left(0.5 \times 10^{6}\right)$ from normal individuals were treated at $37^{\circ} \mathrm{C}$ for $16 \mathrm{~h}$ with: (a) normal sera $(n=10) ;(b)$ IFN- $\alpha, 100 \mathrm{U} / \mathrm{ml}(n=7) ;(c)$ IFN- $\gamma, 100 \mathrm{U} / \mathrm{ml}(n=6) ;(d)$ sera from patients with HIV group IVc infection $(n=4) ;(e) \mathrm{TNF}, 10 \mathrm{U} / \mathrm{ml}(n=7)$. After washings the cells were incubated at $37^{\circ} \mathrm{C}$ for $16 \mathrm{~h}$ in the presence (solid bars) or absence (open bars) of LPS $(10 \mu \mathrm{g} / \mathrm{ml})$. Triplicate samples of the culture medium were assayed for TNF levels.

sensitize normal BM to LPS stimulation (results not shown). It therefore appears that the acid-labile IFN- $\alpha$ present in AIDS sera is responsible for the hypersensitivity of BM to LPS stimulation.

Synergistic interaction of IFN- $\alpha$ or $-\gamma$ with LPS on TNF synthesis. Since pretreatment of normal BM with IFN results in hypersensitivity to LPS, we determined the interaction of IFN- $\alpha$ or $-\gamma$ with LPS on the induction of TNF synthesis (Fig. 4). Normal BM responded to LPS with a concentration-dependent induction of TNF (Fig. $4 A$ ). When the cells were treated with IFN- $\alpha$ or $-\gamma$ in combination with LPS, there was a synergistic induction of TNF synthesis (Fig. $4 A$ ). For example, at low concentrations of LPS $(1.0 \mu \mathrm{g} / \mathrm{ml})$ in the absence of IFN- $\alpha$ or $-\gamma$ the level of TNF in the medium was $20 \pm 6.0 \mathrm{U} / \mathrm{ml}$ $(n=5)$. Simultaneous treatment of the cells with either IFN- $\alpha$ or $-\gamma$ at this LPS concentration resulted in increased synthesis of TNF to $64 \pm 20$ and $152 \pm 47 \mathrm{U} / \mathrm{ml}$, respectively $(n=5)$. At high concentrations of LPS, such as $100 \mu \mathrm{g} / \mathrm{ml}$, the extent of IFN- $\alpha$ or $-\gamma$ enhancement of LPS induction of TNF was less remarkable (Fig. $4 A$ ).

Similarly, the extent of IFN enhancement of LPS induction of TNF synthesis depends on the concentration of IFN- $\alpha$ or $-\gamma$ in the incubation medium. IFN- $\alpha$ by itself has minimal effects on the induction of TNF synthesis (Fig. $4 \mathrm{~B}$ ). However, normal BM, when treated simultaneously with LPS (1.0 $\mu \mathrm{g} / \mathrm{ml}$ ) and various concentrations of IFN $-\alpha$ or $-\gamma$, showed significant induction of TNF synthesis (Fig. 4, $B$ and $C$ ). It appears that IFN- $\gamma$ is a more potent enhancer of TNF synthesis with levels of TNF up to $560 \pm 260 \mathrm{U} / \mathrm{ml}(n=5)$ in the incubation medium (Fig. $4 C$ ). When cells were treated with LPS, IFN- $\alpha$, and IFN- $\gamma$ simultaneously we did not observe further synergistic induction of TNF as compared with the LPS and IFN- $\gamma$ treatment (results not shown).

\section{Discussion}

TNF $\alpha$ is a soluble polypeptide produced by activated monocytes and macrophages upon exposure to bacterial or proto- 

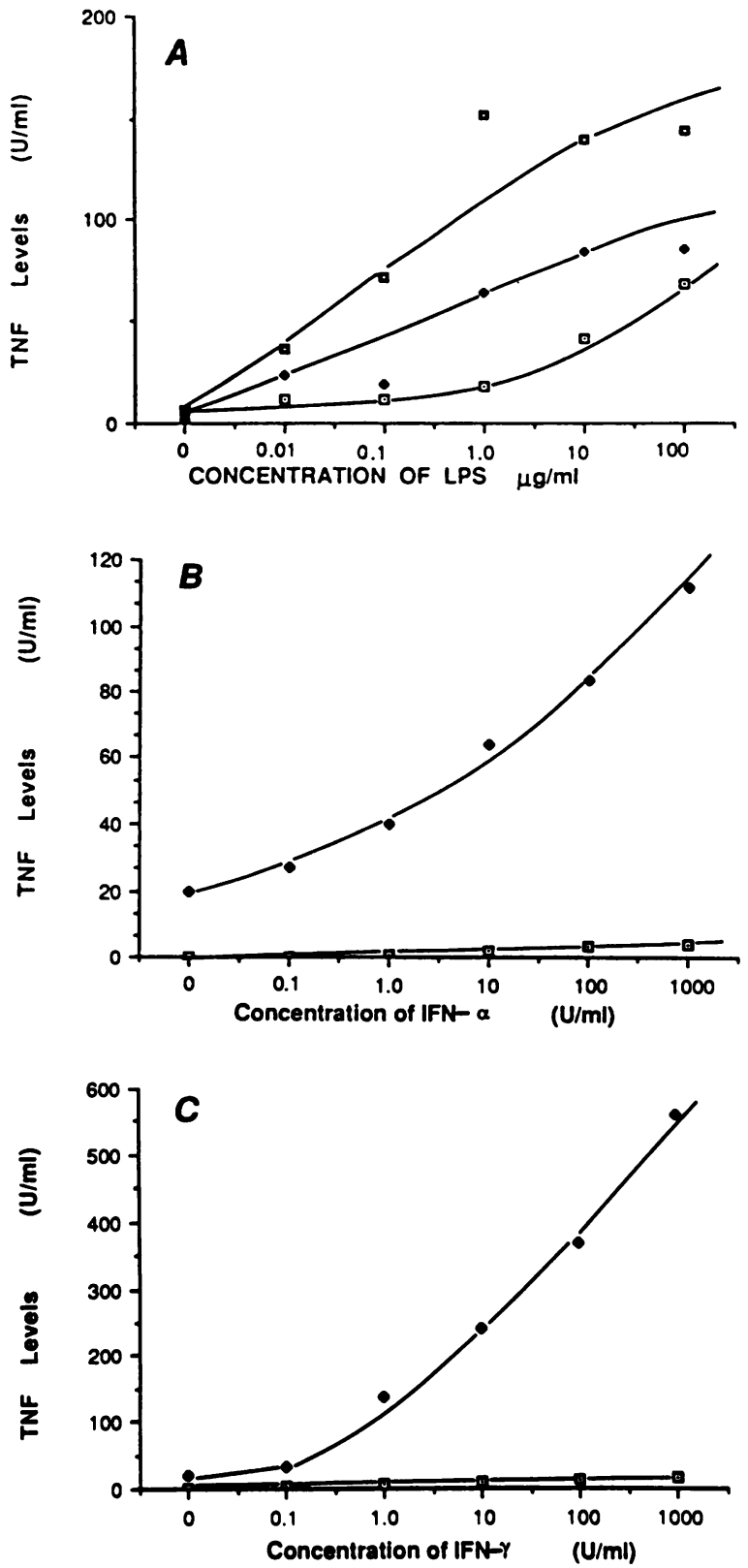

Figure 4. Synergistic interaction of LPS with IFN- $\alpha$ and $-\gamma$. Normal BM $\left(0.5 \times 10^{6}\right)$ were treated with: $(A)$ Indicated concentrations of LPS with or without IFN- $\alpha$ or $-\gamma(100 \mathrm{U} / \mathrm{ml})$. $\square$, Controls, no IFN; • IFN $-\alpha$; $\square$, IFN- $\gamma$. (B) Indicated concentrations of IFN- $\alpha$ with or without LPS $(1.0 \mu \mathrm{g} / \mathrm{ml})$. $₫$, Controls, no LPS; $\bullet$, LPS. $(C)$ Indicated concentrations of IFN- $\gamma$ with or without LPS $(1.0 \mu \mathrm{g} / \mathrm{ml})$. $\square$, Controls, no LPS; $\diamond$, LPS. After incubations at $37^{\circ} \mathrm{C}$ for $16 \mathrm{~h}$ triplicate samples of the culture supernatants were assayed for TNF levels. Each point represents the mean level of TNF in five experiments; SD were $<25 \%$ about the mean.

zoal products (10, 21-23). In addition to its role in the elimination of pathogens, TNF is thought to contribute to cytotoxicity and cytostasis in other immune processes including tumor destruction and autoallergic reactions $(10,11)$. Recent reports indicate that TNF is a potent mediator of inflammation and cachexia $(10,11,23)$. Synthesis of TNF by blood monocytes and macrophages is regulated by cytokines including IFNs, foreign antigens, and bacterial products such as LPS (11-14).

Since high levels of the acid-labile IFN- $\alpha$ present in the sera of patients with HIV infections have been implicated in the pathogenesis of AIDS (1-5), we investigated whether this IFN- $\alpha$ subtype is capable of activating the TNF system by inducing the synthesis of TNF. In this paper we show that blood monocytes from AIDS patients spontaneously produce high levels of TNF and are hypersensitive to LPS stimulation, resulting in further induction of TNF synthesis in vitro (Fig. 1).

We have determined the agent in AIDS sera responsible for induction of TNF synthesis by BM is the acid-labile IFN- $\alpha$. Normal BM when treated with AIDS sera containing high levels of the acid-labile IFN- $\alpha$ produce high levels of TNF (Fig. $2 d$ ). Similar treatment of normal BM in the presence of antiIFN- $\alpha$ antibodies results in an $80 \%$ reduction in TNF synthesis (Fig. $2 e$ ). Further, sera from normal controls and patients with HIV group III infection (containing low levels of the acid-labile IFN- $\alpha$ ) do not induce TNF synthesis (Fig. 2, $b$ and $c$ ). These results strongly suggest that the agent in AIDS sera responsible for the majority of the TNF induction is the acid-labile IFN- $\alpha$. However, it is possible that the IFN subtype serves as a cofactor with other as yet unidentified agents, as the serum factors responsible for the balance of the TNF induction (Fig. $2 e)$ remain to be determined.

In determining the mechanism of hypersensitivity of the AIDS cells to LPS stimulation, we have shown that the same phenomenon can be reproduced in normal BM if the cells are pretreated with IFN- $\alpha$, IFN- $\gamma$, or AIDS sera containing the acid-labile IFN- $\alpha$ (Fig. 3). Neutralization of the AIDS sera with anti-IFN- $\alpha$ antibodies abrogates this hypersensitivity while anti-IFN- $\gamma$ antibodies do not (results not shown). Therefore, sensitization of BM from AIDS patients to LPS stimulation is probably due to high levels of the acid-labile IFN- $\alpha$ in their sera.

Synergistic interactions of LPS and IFN on the induction of soluble proteins involved in inflammation, specifically IL-1 and factor B of the alternate complement pathway, have previously been reported $(15,16)$. Synergism has also been studied for tumor cell killing in macrophages where IFN- $\gamma$ enhances the sensitivity of the macrophages to LPS stimulation, resulting in increased cytotoxic and tumoricidal activities (13, 14). In evaluating the interaction of IFN- $\alpha$ and $-\gamma$ with LPS we have shown that IFN- $\alpha$ or $-\gamma$ enhances the induction of TNF by LPS at IFN concentrations as low as $1 \mathrm{U} / \mathrm{ml}$ in vitro (Fig. 4). This low level of IFN is entirely within the physiological range. As discussed above, the levels of the acid-labile IFN- $\alpha$ present in sera from AIDS patients are as high as $350 \pm 160$ $\mathrm{U} / \mathrm{ml}$ (see Results). It is therefore conceivable that high levels of the IFN- $\alpha$ subtype in these patients provide suitable conditions for the LPS induction of TNF synthesis in vivo during sepsis.

Experimental animals including mice, rats, and rabbits, when injected with gram-negative bacteria or LPS, produce high levels of TNF $(23,24)$. The released cytokine induces severe metabolic acidosis, hypotension, and hemorrhagic necrosis of organs including adrenal gland, kidney, and lung (23-25). On the cellular level, it is known that TNF causes neutrophil degranulation, production of superoxide anions and hydrogen peroxide $(26,27)$, induction of procoagulant 
activity, and suppression of thrombomodulant synthesis in endothelial cells (28). These pathophysiological processes are ameliorated if the animals are pretreated with a neutralizing MAb against TNF $(29,30)$. Thus, TNF has been shown to be a potent mediator of septic shock.

Recent reports indicate that gram-negative bacterial sepsis in AIDS patients is frequently associated with hypotension, respiratory failure, and high case fatality rate $(31,32)$. In these patients it is possible that LPS interacts synergistically with the acid-labile IFN- $\alpha$ present in the plasma to produce high levels of TNF in vivo. Consequently, the pathophysiological processes described above are induced by the cytokine, resulting in clinical deterioration of the patients during sepsis.

Details of the cellular mechanisms underlying the spontaneous production of TNF and the hypersensitivity to LPS stimulation in AIDS patients remain to be investigated. Our observation suggests that high levels of the acid-labile IFN- $\alpha$ subtype in AIDS sera contribute significantly to the enhancement of TNF synthesis. This enhancement of TNF synthesis could also occur through sensitization of the cells to repetitive exposure to viral, bacterial, or other foreign antigens in vivo. The role of HIV gene products, such as the envelope proteins, in contributing to the activation phenomenon must also be considered.

In conclusion, activation of the TNF system by the acidlabile IFN- $\alpha$ may contribute to physiologic disturbances such as the wasting syndrome observed in AIDS. Furthermore, the acid-labile IFN- $\alpha$ may play a key role in the pathophysiological changes, in particular the enhancement of TNF synthesis, involved in septic shock in AIDS patients.

\section{Acknowledgments}

The authors wish to thank Dr. S. E. Read for his generous support in providing patient materials, and Dr. B. R. G. Williams and Dr. R. Gold for their critical comments. We also wish to thank Dr. M. Shepard, Genentech Inc., for supplying preparations of recombinant DNA-derived Hu-TNF $\alpha$ and anti-TNF $\alpha$ antibodies.

This work was supported by grants from the Federal Center for AIDS and the National Health Research and Development Program, Department of National Health, Canada. Dr. Lau is the recipient of an I.C.I. Pharma Research Award from the Canadian Infectious Disease Society.

\section{References}

1. DeStefano, E., R. M. Friedman, A. E. Friedman-Kien, J. J. Goedert, D. Henriksen, O. T. Preble, J. A. Sonaadend, and J. Vilcek. 1982. Acid-labile human leukocyte interferon in homosexual men with Kaposi's sarcoma and lymphadenopathy. J. Infect. Dis. 146:451455.

2. Eyster, M. E., J. J. Goedert, M. C. Poon, and O. T. Preble. 1983. Acid-labile alpha interferon: a possible preclinical marker for the acquired immune deficiency syndrome in hemophiliac patients. $N$. Engl. J. Med. 309:583-586.

3. Read, S. E., B. R. G. Williams, R. A. Coates, W. K. Evans, M. M. Fanning, B. M. Garvey, and F. A. Shepherd. 1985. Elevated levels of interferon-induced 2-5A synthetase in generalized persistent lymphadenopathy and AIDS. J. Infect. Dis. 152:466-472.

4. Read, S. E., J. LeBrocq, and B. R. G. William. 1985. Persistent elevation of 2-5A synthetase and prognosis in the AIDS-related com- plex. In The 2-5A System. B. R. G. Williams and R. Silverman, editors. Alan R. Liss, Inc., New York. 405-413.

5. Lau, A. S., S. E. Read, and B. R. G. Williams. 1988. Downregulation of interferon $\alpha$ but not $\gamma$ receptor expression in vivo in the acquired immunodeficiency syndrome. J. Clin. Invest. 82:1415-1421.

6. Wong, G. H. W., and D. V. Goeddel. 1986. Tumor necrosis factor $\alpha$ and $\beta$ inhibit virus replication and synergize with interferons. Nature (Lond.). 323:819-822.

7. Williamson, B. D., and L. J. Old. 1983. Human tumor necrosis factor produced by human B-cell lines: synergistic cytotoxic interaction with human interferon. Proc. Natl. Acad. Sci. USA. 80:53975401.

8. Williams, T. W., and J. A. Bellant. 1983. In vitro synergism between interferons and human lymphotoxin: enhancement of lymphotoxin-induced target cell killing. J. Immunol. 130:518-520.

9. Stone-Wolff, D. S., Y. K. Yip, H. C. Kelker, J. Le, D. DeStefano, B. Y. Rubin, E. Rinderknecht, B. B. Aggarwal, and J. Vilcek. 1984. Interrelationships of human interferon gamma with lymphotoxin and monocyte cytotoxin. J. Exp. Med. 159:828-843.

10. Ruddle, N. H. 1985. Lymphotoxin redux. Immunol. Today. 6:156-159.

11. Beutler, B., and A. Cerami. 1987. Cachectin: more than a tumor necrosis factor. N. Engl. J. Med. 316:379-385.

12. Beutler, B., V. Tkacenko, I. Milsark, N. Krochin, and A. Cerami. 1986. Effect of $\gamma$ interferon on cachectin expression by mononuclear phagocytes. J. Exp. Med. 164:1791-1796.

13. Pace, J. L., and S. W. Russell. 1981. Activation of mouse macrophages for tumor cell killing. I. Quantitative analysis of interactions between lymphokine and lipopolysaccharide. J. Immunol. 126:1863-1867.

14. Akagawa, K. S., and T. Tokunaga. 1985. Lack of binding of bacterial lipopolysaccharide to mouse lung macrophages and restoration of binding by $\gamma$ interferon. J. Exp. Med. 162:1444-1459.

15. Candler, R. V., B. T. Rouse, and R. N. Moore. 1985. Regulation of interleukin 1 production by alpha and beta interferons: evidence for both direct and indirect enhancement. J. Interferon Res. 5:179-189.

16. Katz, Y., F. S. Cole, and R. C. Strunk. 1988. Synergism between $\gamma$ interferon and lipopolysaccharide for synthesis of factor B, but not C2, in human fibroblasts. J. Exp. Med. 167:1-14.

17. Centers for Disease Control Report. 1986. Classification system for human T-lymphotropic virus type III/lymphadenopathy-associated virus infections. Morbid. Mortal. Weekly Rep. 35:334-339.

18. Lau, A. S., G. E. Hannigan, and B. R. G. Williams. 1986. Regulation of interferon receptor expression in human blood lymphocytes in vitro and during interferon therapy. J. Clin. Invest. 77:16321638.

19. Aggarwal, B. B., T. E. Essalu, and P. E. Hass. 1985. Characterization of receptors for human tumor necrosis factor and their regulation by IFN- $\gamma$. Nature (Lond.). 318:665-667.

20. Ruggiero, V., J. Tanvernier, W. Fiers, and C. Baglioni. 1986. Induction of the synthesis of tumor necrosis factor receptors by interferon $\gamma$. J. Immunol. 136:2445-2450.

21. Carswell, E. A., L. Old, R. L. Kassel, S. Green, N. Fiore, and B. Williamson. 1975. An endotoxin-induced serum factor that causes necrosis of tumors. Proc. Natl. Acad. Sci. USA. 72:3666-3670.

22. Williams, T. W., and G. A. Granger. 1968. Lymphocyte in vitro cytotoxicity: lymphotoxins of several mammalian species. Nature (Lond.). 219:1076-1077.

23. Cerami, A., and B. Beutler. 1988. The role of cachectin/TNF in endotoxic shock and cachexia. Immunol. Today. 9:28-31.

24. Abe, S., T. Gatanaga, M. Yamazaki, G. Soma, and D. Mizuno. 1985. Purification of rabbit tumor necrosis factor. FEBS (Fed. Eur. Biochem. Soc.) Lett. 180:203-206. 
25. Tracey, K. J., B. Beutler, S. F. Lowry, T. Merryweather, S. Wolpe, I. W. Milsark, R. J. Hariri, T. J. Fahey, A. Zentella, J. D. Albert, G. T. Shires, and A. Cerami. 1986. Shock and tissue injury induced by recombinant human cachectin (TNF). Science (Wash. DC). 234:470-473.

26. Klebanoff, S. J., M. A. Vadas, J. M. Harlan, L. H. Sparks, J. R. Gamble, J. M. Agosti, and A. M. Waltersdorph. 1986. Stimulation of neutrophils by tumor necrosis factor. J. Immunol. 136:4220-4225.

27. Tsujimoto, M., S. Yokota, J. Vilcek, and G. Weissman. 1986. Tumor necrosis factor provokes anion generation from neutrophils. Biochem. Biophys. Res. Commun. 137:1094-1100.

28. Nawroth, P. P., and D. M. Stern. 1986. Modulation of endothelial cell hemostatic properties by tumor necrosis factor. J. Exp. Med. 163:740-745.
29. Mathison, J. C., E. Wolfson, and R. J. Ulevitch. 1988. Participation of tumor necrosis factor in the mediation of gram-negative bacterial lipopolysaccharide-induced injury in rabbits. J. Clin. Invest. 81:1925-1937.

30. Tracey, K. J., Y. Fong, D. G. Hesse, K. R. Manogue, A. T. Lee, G. C. Kuo, S. F. Lowry, and A. Cerami. 1987. Anti-cachectin/TNF monoclonal antibodies prevent septic shock during lethal bacteremia. Nature (Lond.). 330:662-664.

31. Shannon, K. M, and A. J. Ammann. 1985. Acquired immune deficiency syndrome in childhood. J. Pediar. 106:332-342.

32. Witt, D. J., D. E. Craven, and W. R. McCabe. Bacterial infections in adult patients with the acquired immune deficiency syndrome (AIDS) and AIDS-related complex. Am. J. Med. 82:900-906. 